\title{
Human-Centered AI to Support an Adaptive Management of Human-Machine Transitions with Vehicle Automation
}

\author{
Thierry Bellet ${ }^{1, *}$, Aurélie Banet ${ }^{2, *}$, Marie Petiot ${ }^{1}$, Bertrand Richard ${ }^{1}$ and Joshua Quick ${ }^{1}$ \\ 1 Laboratory of Ergonomics and Cognitive Sciences Applied to Transport (LESCOT), Gustave Eiffel University, \\ 69675 Lyon, France; marie.petiot@ifsttar.fr (M.P.); bertrand.richard@univ-eiffel.fr (B.R.); \\ joshua.quick@ifsttar.fr (J.Q.) \\ 2 Laboratory of Accident Mechanism Analysis (LMA), Gustave Eiffel University, 13300 Salon-de-Provence, France \\ * Correspondence: thierry.bellet@univ-eiffel.fr (T.B.); aurelie.banet@univ-eiffel.fr (A.B.)
}

Citation: Bellet, T.; Banet, A. Petiot, M.; Richard, B.; Quick, J. Human-Centered AI to Support an Adaptive Management of Human-Machine Transitions with Vehicle Automation. Information 2021, 12, 13. https://doi.org/10.3390/ info12010013

Received: 1 October 2020 Accepted: 23 December 2020 Published: 31 December 2020

Publisher's Note: MDPI stays neutral with regard to jurisdictional clai$\mathrm{ms}$ in published maps and institutional affiliations.

Copyright: (C) 2020 by the authors. Licensee MDPI, Basel, Switzerland. This article is an open access article distributed under the terms and conditions of the Creative Commons Attribution (CC BY) license (https:// creativecommons.org/licenses/by/ $4.0 /)$.
Abstract: This article is about the Human-Centered Design (HCD), development and evaluation of an Artificial Intelligence (AI) algorithm aiming to support an adaptive management of HumanMachine Transition (HMT) between car drivers and vehicle automation. The general principle of this algorithm is to monitor (1) the drivers' behaviors and (2) the situational criticality to manage in real time the Human-Machine Interactions (HMI). This Human-Centered AI (HCAI) approach was designed from real drivers' needs, difficulties and errors observed at the wheel of an instrumented car. Then, the HCAI algorithm was integrated into demonstrators of Advanced Driving Aid Systems (ADAS) implemented on a driving simulator (dedicated to highway driving or to urban intersection crossing). Finally, user tests were carried out to support their evaluation from the end-users point of view. Thirty participants were invited to practically experience these ADAS supported by the HCAI algorithm. To increase the scope of this evaluation, driving simulator experiments were implemented among three groups of 10 participants, corresponding to three highly contrasted profiles of endusers, having respectively a positive, neutral or reluctant attitude towards vehicle automation. After having introduced the research context and presented the HCAI algorithm designed to contextually manage HMT with vehicle automation, the main results collected among these three profiles of future potential end users are presented. In brief, main findings confirm the efficiency and the effectiveness of the HCAI algorithm, its benefits regarding drivers' satisfaction, and the high levels of acceptance, perceived utility, usability and attractiveness of this new type of "adaptive vehicle automation".

Keywords: Human-Centered Design (HCD); Human-Centered Artificial Intelligence (HCAI); Vehicle Automation; Human-Machine Transition (HMT); driver monitoring; adaptive HMI; User Experience (UX)

\section{Introduction}

With the recent progress in vehicle automation, a new generation of Advanced Driving Aid Systems (ADAS) based on Artificial Intelligence (AI) is progressively emerging on the market. From a driving task fully managed by the humans, we are now heading towards a co-managed task performed by a joint cognitive system [1]. According to this new deal, the decision and the way to activate vehicle automation in order to assist, to support or to replace the human driver must not only take into account the technological capabilities of AI systems: it is also crucial to consider the drivers' abilities and characteristics to design vehicle automation able to interact with users in an appropriate way [2-5].

Another important issue for vehicle automation designers concerns drivers' assessments regarding the interests of automated driving systems when compared to manual driving. Facing to the new opportunities opened by vehicle automation, it is essential to take into consideration end users' acceptance (or reluctance) of this new way of driving. According to models explaining the adoption of a technology, like the technology acceptance model of Davis [6] or the unified theories of acceptance and use of technology [7], 
acceptance of new technologies is intimately linked with their perceived usefulness and efficiency compared to manual driving [8].

To increase drivers' acceptance and benefits of vehicle automation for road safety, one solution is to design adaptive driving aid systems based on AI technics aiming to adapt their behaviors and human-machine (H-M) interactions depending on human driver's specific needs in the current traffic conditions [9].

However, in order to manage accordingly H-M interactions and/or transitions in vehicle control, such context-based management requires to specify, design and develop a set of monitoring functions associated with an intelligent decision making process able to assess in real time situational risks and difficulties experienced by the driver.

This article is specifically dedicated to the development of an AI algorithm in charge of providing a contextual management of human-machine transitions (HMT) between drivers and car automation.

To support this joint-approach in ergonomics design and cognitive engineering, an integrated human-centered design (HCD) method was deployed at 5 complementary levels, which will be successively presented in this paper as following:

(1) Theoretical foundations (Section 2.1): related to human-machine transitions in the specific area of driving assistances.

(2) Ergonomics requirements (Section 2.2): towards future driving aids based-on vehicle automation, from the analysis of drivers' errors recorded in a pre-existing naturalistic dataset.

(3) Design and development of the AI algorithm (Section 3): to support the adaptive management of HMT in future vehicles.

(4) Demonstrator implementation on driving simulator (Section 4): to allow future end users to practically experience interactions with this innovative solution of AI-based automation.

(5) Evaluation of this AI-based solution (Section 5): from the end user's point of view.

By placing the human driver at the center of all the stages of this HCD process, it is expected that the adaptive HMT management of vehicle automation will provide benefits regarding end users' acceptance and satisfaction, as well as in terms of ADAS usefulness, usability and attractiveness. Discussion of the results, presented in Section 6, will further examine this last issue.

\section{Human-Centered Design: Theoretical Foundations and Requirements towards Future Solutions of Vehicle Automation Based on AI Technics}

\subsection{A Theoretical Framework for Vehicle Automation: The Human-Machine Transition Cycle (HMT)}

The starting point of this research was the theoretical HMT cycle initially proposed by Bellet et al. [10] to define advanced monitoring functions by jointly considering humanmachine interaction (HMI) implications, on the one hand, and legal or ethical issues, in the other. From this HMT framework (presented in Figure 1), two main issues are of prior importance: the modalities of interactions and the types of transitions.

Modalities of interactions refer to the way to interact with the driver from the HMI. According to the driver's needs and the criticality of the driving situation, the cooperation gradient to interact may be (1) to deliver information, (2) to generate warning, or (3) to take-over/handover the vehicle control.

Types of transitions refer to the driving mode (i.e., manual versus automated), and depend on the initial state in the loop of control. In case of manual driving (from Level 0 to 2 of the Society of Automotive Engineers classification [11]) as initial state (i.e., corresponding to the red section in Figure 1), monitoring functions have to assess risks (related to the drivers' behavior or to the external driving conditions), and then to activate the HMI modalities accordingly to assist the driver from information or warning delivery to vehicle takeover. From this part of the HMT cycle, automatic takeover transitions due to drivers' errors or dangerous behaviors are one of the two ways to manage the transitions 
from manual to automated driving. The second one corresponds to deliberate transitions triggered by the drivers themselves to transfer the car control towards vehicle automation.

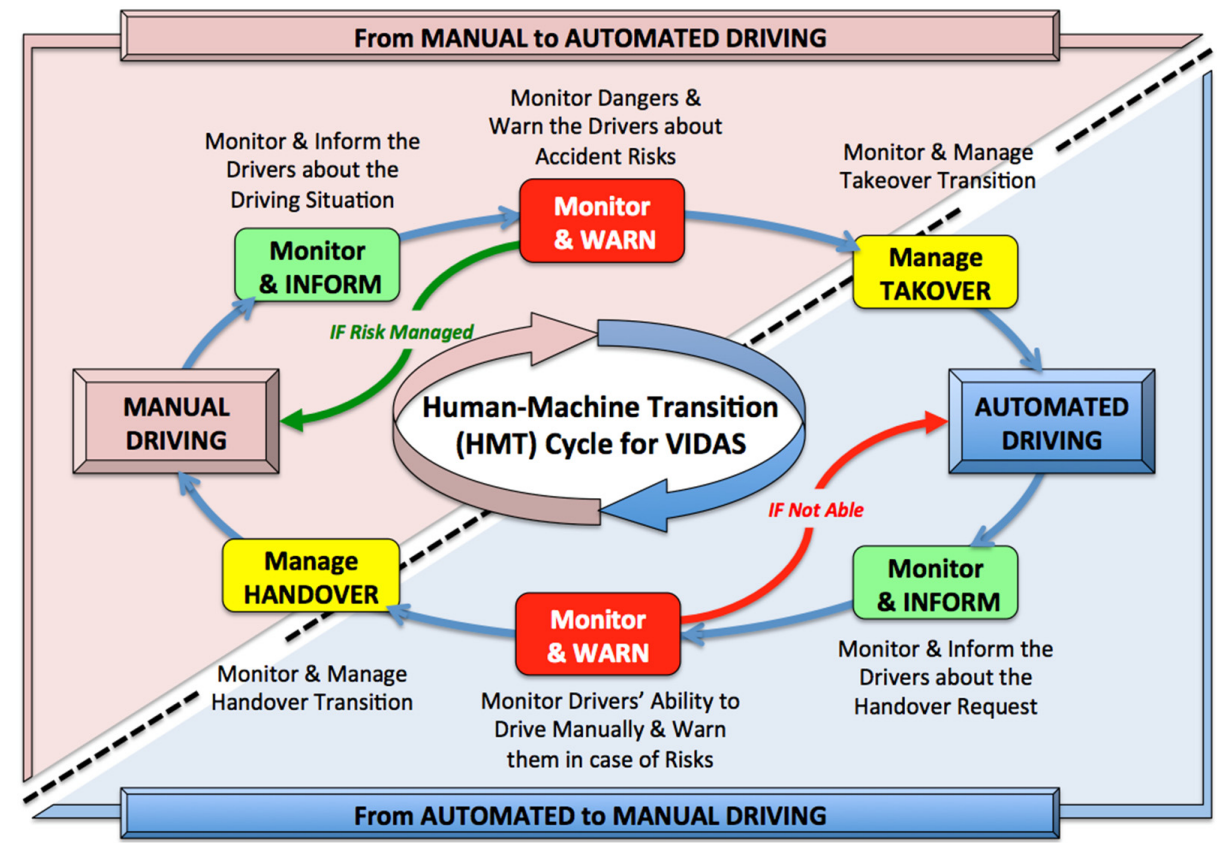

Figure 1. The Human-Machine Transition (HMT) framework [10].

In case of automated driving (from SAE Level 3 to 5) as initial state (i.e., corresponding to the blue section in Figure 1), monitoring functions have to assess automated system limits and/or driving tasks requiring a transfer of the vehicle control from the automation to the human driver, and then to adequately support this transition. In this part of the cycle, a crucial issue regarding H-M interactions is to generate a take-over request to the driver, and then to manage the handover transitions (i.e., from automated to manual driving) when the driver seems able to safely resume the manual control of the car.

\subsection{From Drivers' Errors Analysis to Requirements for Human-Centered Vehicle Automation}

To better integrate human drivers' needs (in terms of road safety) into the design process of the AI technics supporting the HMT management of future advanced cars, a Human-Centered Design (HCD) method was first deployed to investigate difficulties experienced by drivers when using the cars of today. In this aim, a pre-existing naturalistic dataset collected among a sample of 99 car drivers was examined.

In brief, data recorded in this database were collected from an instrumented car to study driving behaviors and performances of vulnerable car drivers. Vulnerable car drivers are defined here as drivers liable to have more difficulties than the others when driving their car, due to the potential negative effects of their old age [12-16], or due to their lack of driving experience (i.e., novice drivers [17-20]. Motivations for using such a pre-existing database collected among vulnerable car drivers in this study was justified by the objective to design ADAS able to assist users who have the highest needs in assistance and who are liable to gain the most benefits from future driving aids. The main sub-group of vulnerable car drivers is composed of 76 elderly drivers, aged of 70 years old or over (48 men and 28 women; mean age of 74.4 years old; [21]). The second sub-group is made of 15 young novices drivers, aged from 18 to 23 years old ( 8 men and 7 women). In addition, a last set of empirical data was collected among 8 middle-aged experienced drivers (6 men and 2 women) to provide comparative data collected among "non-vulnerable" car drivers.

During the data collection, a driving instructor was present in the car (sitting in the front passenger seat) to monitor the driver and to ensure road safety (from verbal interventions or by taking the control of the vehicle). However, the scientific instructions 
given to the instructor was to not intervene or comment any drivers' error during the driving task, except if assessed as mandatory for ensuring road safety. Empirical data were recorded among all the participants while driving the same instrumented car along a similar route. The trip performed by the participants was $28.3 \mathrm{~km}$ long, including urban (13 km), semi-urban or rural areas $(5 \mathrm{~km})$, and highway sections $(10 \mathrm{~km})$. The mean duration required to perform this route was of $50 \mathrm{~min}$ of driving. At last, the naturalistic data collected represent a total of $2800 \mathrm{~km}$ covered and $82 \mathrm{~h}$ of recording. This material permitted the in-depth analysis of 3960 intersection crossings, 890 lane change manoeuvers and 198 entries on the highway. In addition, nearly 2000 driving performance evaluation scores were also attributed by the driving instructor (responsible for monitoring the drivers during the experiment). Moreover, more than $240 \mathrm{~h}$ of post-driving interviews were held with the participants immediately after the driving task to collect their evaluations regarding both the criticality of the driving situations and the self-assessment related to their own driving performances, difficulties and errors [21].

The exploitation of this naturalistic database in this new study permitted the identification of 271 situations for which the sample of vulnerable car drivers (i.e., elderly people or young novices) experienced a difficulty when driving, whether or not they were aware about their driving errors. In terms of driving situations, the main difficulties and the highest numbers of errors occurred during intersection crossing (141 cases corresponding to $52 \%$ of the observed driving errors), more particularly when the drivers have to perform a left-turn manoeuver at urban crossroads (49 cases and 18\% of the errors). A typical example of vulnerable car drivers' errors observed during left-turn is presented in Figure 2. This near accident case was due to the driver's misperception of an incoming vehicle having generated a dangerous decision to cross. The collision was avoided thanks to an emergency braking of the driving instructor.

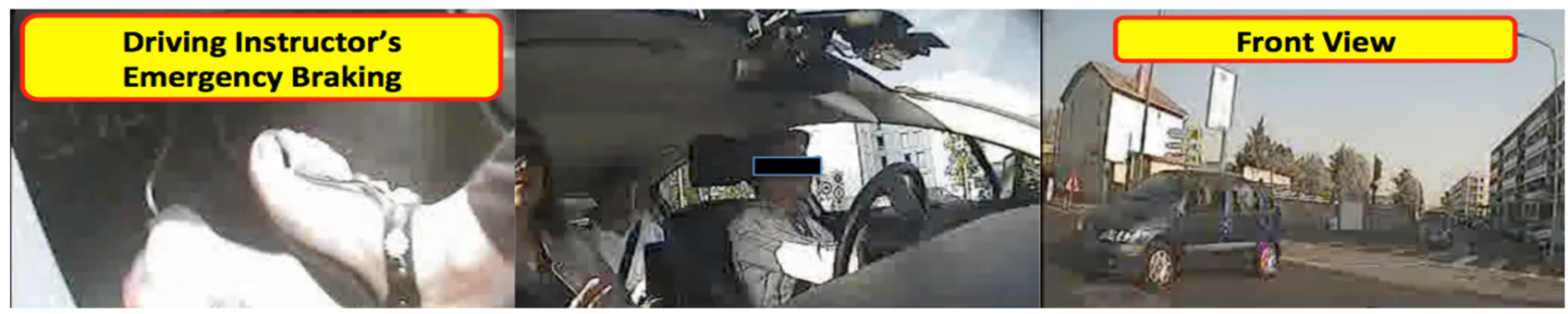

Figure 2. Example of a typical errors made by vulnerable car drivers when implementing a left-turn manoeuver at urban crossroads.

Regarding the highway context, the main difficulties occurred when the drivers had to implement a lane change manoeuver for following their destination, to overtake another vehicle, and to enter or leave the highway (61 cases, corresponding to $23 \%$ of the driving errors collected).

The two following figures present two typical examples of difficulties experienced by vulnerable car drivers when implementing a lane change on highway (on the left and on the right) these difficulties and errors.

In the first example (Figure 3), the driver (older female) decided to overtake a slow car after having un-appropriately checking the left mirror. When she activated the left indicators to change of lane, a motorcyclist switching between rear vehicles suddenly approached to our car with a high speed. To avoid the collision, the driving instructor took the control of the steering wheel to stop the dangerous lane changing manoeuver already started by the driver.

The second typical example of critical lane change extracted from the naturalistic database is presented in Figure 4. In this driving situation, the driver (older male) had to reach the right lane in a merging area, in order to follow his destination. To perform this manoeuver, he glanced several times the right mirror and he detected a car coming from behind on the right lane (seeable in the rear view of Figure 3). However, the driver overestimated the distance and/or underestimated the speed of this approaching car. Then, 
he made the decision to activate the left indicator and to implement a critical lane change. To avoid the collision, the other driver braked and honked our participant, who was highly surprised by this rudeness.

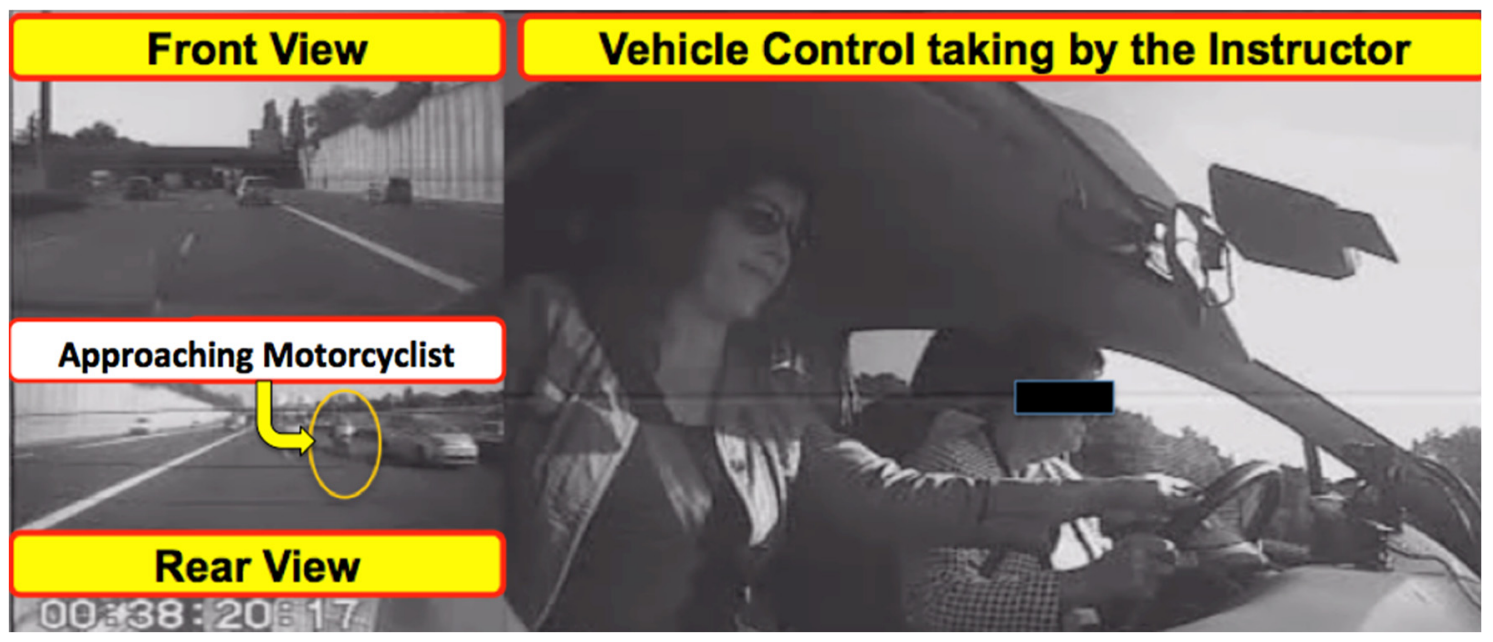

Figure 3. Typical example of driving error during a lane change (on the left) on highway.

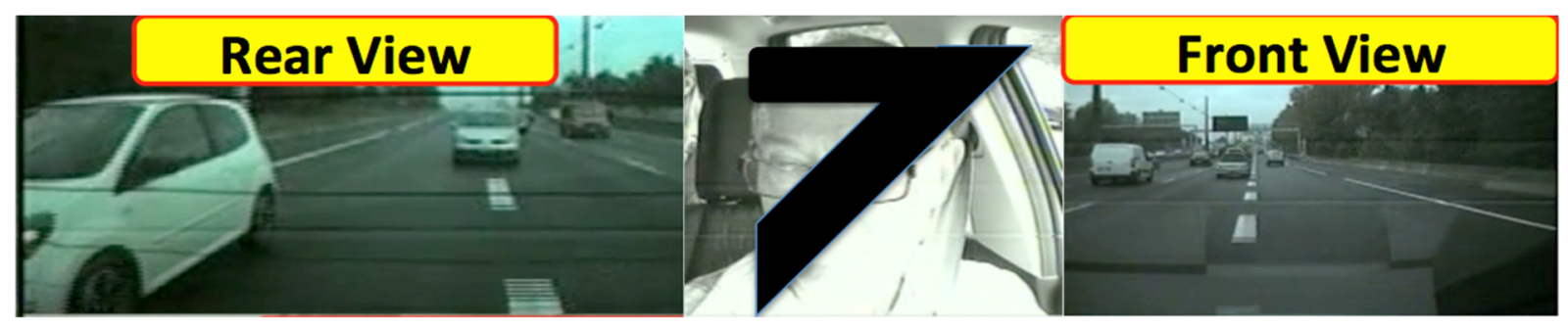

Figure 4. Typical example of driving error during a lane change (on the right) on highway.

From the in-depth analyses of drivers' difficulties and errors recorded in the naturalistic database, three driving aids based on vehicle automation were identified as more particularly useful to assist these vulnerable drivers in the future: an Advanced Intersection Crossing driving Aid (i.e., AICA) focused on urban driving, and two Advanced Highway Driving Aids (i.e., AHiDA), respectively dedicated to Manual driving monitoring (i.e., AHiDA-M) and Automated driving monitoring (i.e., AHiDA-A). When combined together to support both manual driving and to perform highway driving in a fully autonomous way, these two last systems cover the entire HMT cycle presented in Figure 1.

The challenge for urban context was to design a driving aid able to support the manual driving when crossing an intersection (e.g., from manual driving monitoring to Automated Emergency Braking, in case of critical errors). For highway context, the challenge was to design two types of driving aids in charge of supporting lane change maneuvers. From the one side, AHiDA-M is in charge of monitoring and assisting the drivers when they manually perform a lane change. The main HMT issue to be assessed by the HCAI is the detection of dangerous maneuvers, requiring different HMI modalities according to risk level (e.g., from information delivery to vehicle control taking by the automated emergency braking or lane keeping system, in case of high collision risks). From the other side, the AHiDA-A system is specifically dedicated to autonomous driving on highway. The main HMI/HMT management challenges to be overcome by the HCAI algorithm are related to critical events or hazard occurrences, that are too complicated for being handled by vehicle automation, and thus requiring a handover transition to the human driver. 


\section{Design and Development of an HCAI Algorithm to Support the Adaptive HMT Management}

Using the Human-Centered Design approach and the HMT framework, a user centric design of an HCAI algorithm was implemented. As a first step, pre-existing naturalistic data collected on the instrumented car were analyzed in order to model the driving activity to be monitored and then supported by the driving aids. Moreover, several indicators were identified in order to evaluate whether the driver's behaviors were adequate. Finally, decision rules were defined to contextually manage the HMT, according to the drivers' behavior adequacy (DBA) assessment.

\subsection{Driving Activity Modelling}

The driving modeling approach deployed in this research was based on the driving schema theory of Bellet et al., 2009 [16] supported by the driving traces analysis method of Georgeon et al. [22], permitting to describe drivers' activity as a set of state-transition diagrams. In this formalism, states correspond to activity phases and the transitions correspond to actions to be accomplished by the driver to progress from one state to another.

Figure 5 provides an example of such a driving schema related to the lane change manoeuver on highway, as modeled for the AHiDA systems. When approaching and then following a Car B, the driver of Car A can make the decision to overtake it, thereby transitioning into another activity phase (i.e., from "following" to "changing of lane"). The goal of the "changing of lane" phase is to reach the left lane. The sub-schema of this phase contains several expected operational behaviors, like (1) activating the left indicator, (2) turning the steering wheel on the left, (3) accelerating, and so on. To make their decision, drivers have to check their left mirror. If another vehicle (e.g., the red car) is approaching on the left lane, lane change may be postponed or aborted, depending on the dangerousness of the manoeuver.

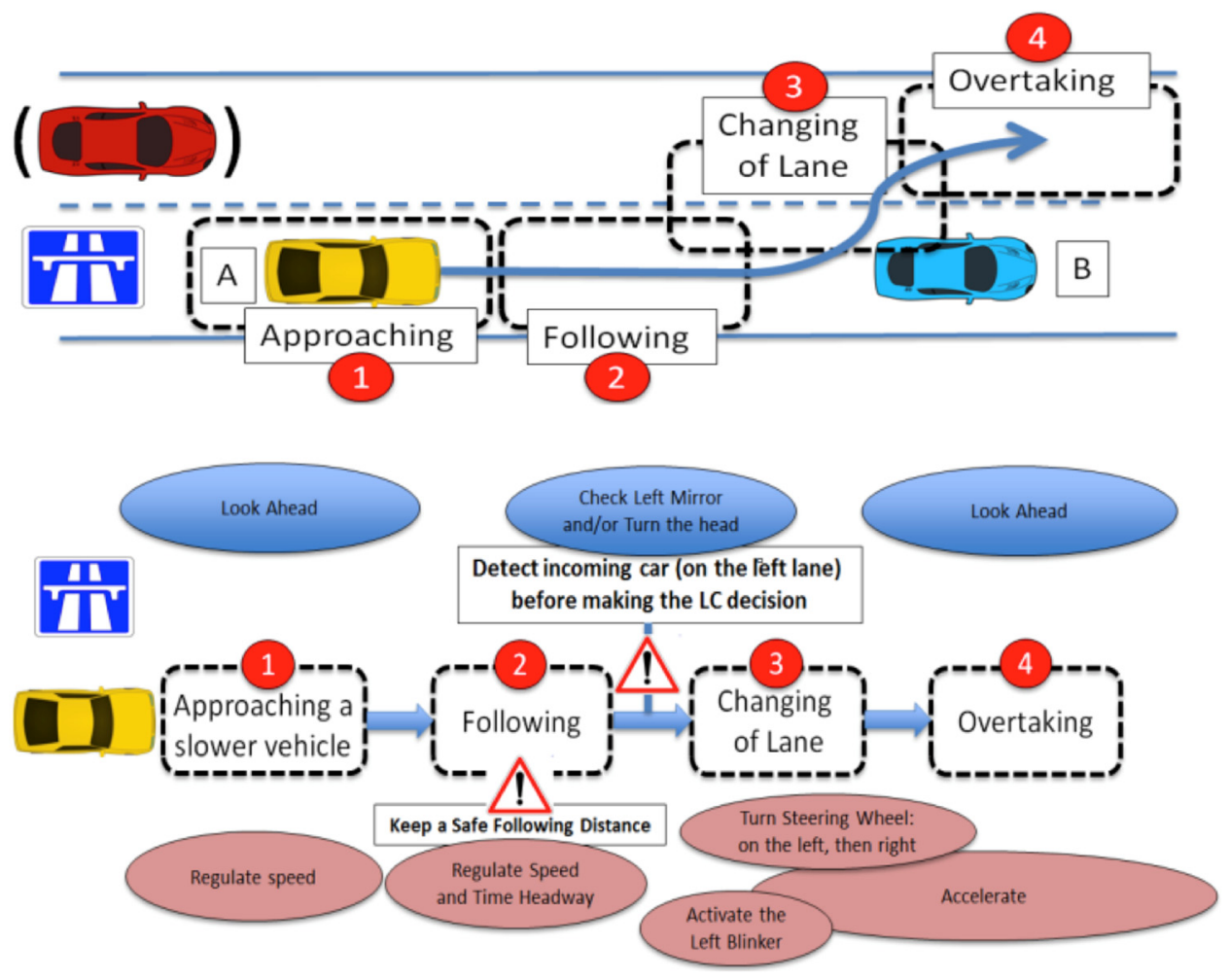

Figure 5. Driving activity modeling and examples of expected behaviors when changing lane on highway.

In association with this driving schema modeling, a set of expected behaviors were identified as actions to be performed for implementing the schema in a safe way (in terms of intervention to be implemented on vehicle commands, visual scanning, or car trajectory 
control, for instance). By contrast, it was also possible to define some unexpected behaviors, corresponding to missing actions, or inappropriate actions implementation (like changing lane without considering the lateral mirror nor activating the indicator).

According to in-depth analyses of the naturalistic driving behaviors implemented through the HCD method, the main errors and difficulties experienced by drivers to safely change lane are associated with the detection of other vehicles approaching on lateral lanes and/or in blind spots, the evaluation of their speed, the identification of a safe gap, and the execution of the lane change manoeuver while visually scanning the surroundings appropriately.

Figure 5 presents different examples of expected behaviors identified from this naturalistic data (i.e., their missing meaning inappropriate behaviors), including both (1) driver's actions on vehicle commands, (2) car status control (cf. red circles in the figure), and (3) visual scanning (cf. blue circles in the figure). All are respectively associated with each of the four "activity phases" of the lane change schema (cf. rectangles with dotted lines).

\subsection{HMT Context-Based Manager Development and Implementation}

The HMT context-based Manager was developed using the RT-Maps software (cf. Figure 6) (https:/ /intempora.com/products/rtmaps.html), as a macro-component in charge to dynamically apply the HMT principles into the driving aids from HCAI technics. Practically, this HMT module acts as a bridge between (a) the observations performed by monitoring functions and (b) the HMI components for delivering information or (c) the car actuators, when a transition toward vehicle automation is required.

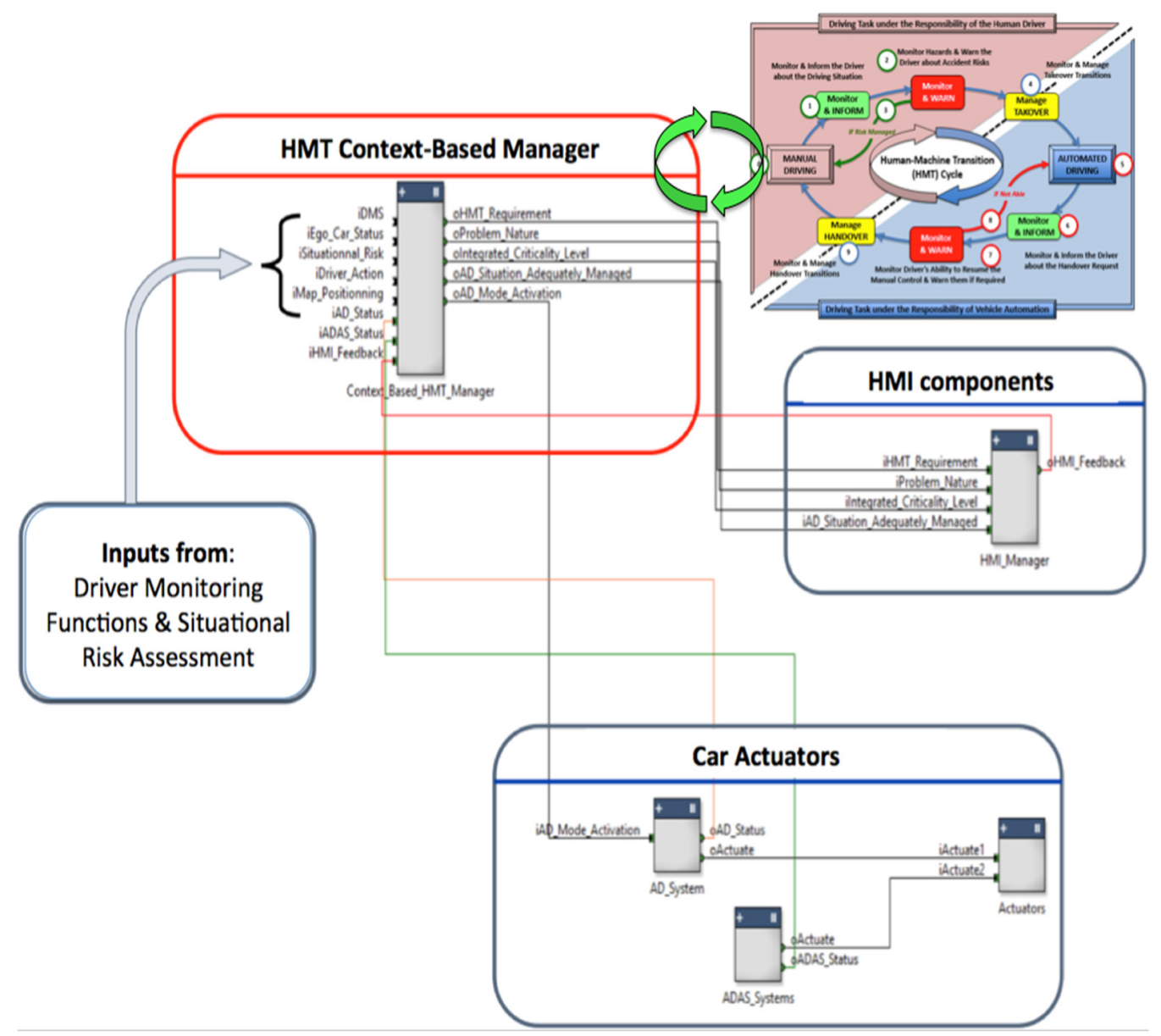

Figure 6. The HMT Manager as implemented with the RT-Maps software of Intempora () 
Internally, this HMT module is based on two sub-modules: the SCA (for situational criticality assessment) and the DBA (for drivers behaviors adequacy). The SCA is in charge of evaluating external risks of collision (mainly based on the computation of lateral and frontal time to collisions with other road users). The DBA provides risk-based analyses to (1) assess to what extent current driving actions are consistent with the driving schema applied, (2) to evaluate their efficiency in the current driving conditions (for instance, sufficient pressure on the brake pedal to manage a front collision risk according to the current time headway and time to collision) and (3) to assess the potential dangerousness of unexpected and/or missing behaviors (e.g., implementing a lane change without any attention paid to the mirrors).

From the outputs generated by the HMT manager, the HMI components (i.e., invehicle displays and loudspeakers) are then activated to deliver pieces of Information or Warning to the driver (according to the level of risk). In addition, in case of dangerous behaviors and/or highly critical situations, the car actuators module may activate two ADAS sub-systems (i.e., automated emergency braking and lane keeping system) to take the control of the car and ensure road safety.

\subsection{HCAI Algorithm to Manage HMT}

The HCAI algorithm developed for managing human-machine transitions and Interactions is presented in Figure 7. This algorithm jointly considers monitoring functions inputs coming from DBA and SCA, in order to determine to what degree the drivers' behaviors are appropriate or dangerous in given driving conditions.

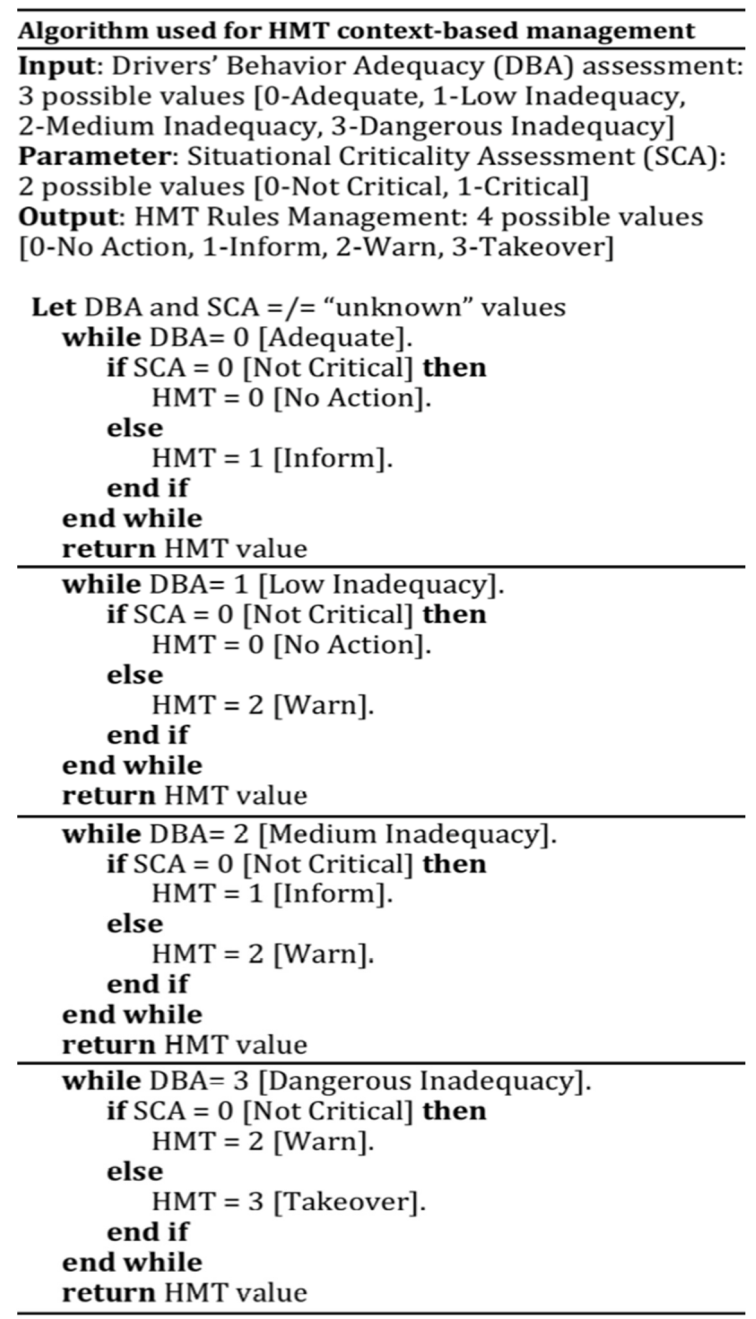

Figure 7. Human centered artificial intelligence (HCAI) algorithm supporting the HMT context-based manager. 
Then, according to this combined assessment, HMT rules management (summarized in Figure 7) are applied, in order to define the best way to interact with the driver in the current driving context.

In AICA and AHiDA demonstrators, as implemented on driving simulator, the HMT Manager is the central decision layer supporting the adaptive management of the different HMI components of the simulated ADAS (i.e., from information or warnings delivery to take-over by vehicle automation).

The more the external risk is assessed as "critical" and the driver's behavior is assessed as "Inadequate", the more the situation is assessed as "dangerous".

However, in case of a high level of external risk combined with an adequate behavior, the global criticality may be assessed as "low", as the situation is considered "under control". By contrast, in case of a "low" risk associated with an inappropriate behavior, the global criticality may be assessed higher than the external risk, due to the inadequate behavior of the driver prone to increase the dangerousness of the driving situation.

\section{A Human-Centered Evaluation Method}

To evaluate the benefit of the HCAI algorithm from the end-users point of view, an integrated demonstrator of this new type of vehicle automation was implemented on a driving simulator (static), allowing the participants to experience these ADAS in an immersive way (as illustrated in Figure 8). Drivers' immersion was supported by 3 High fidelity TV curved screens $\left(1236 \times 714.9 \times 104.0 \mathrm{~mm}^{3}\right.$, corresponding to a field of view of $\left.120^{\circ}\right)$ and spatialized audio, interfaced with a realistic simulation platform of vehicles and road environment, specifically designed to support the virtual human-centered design of vehicle automation [23].

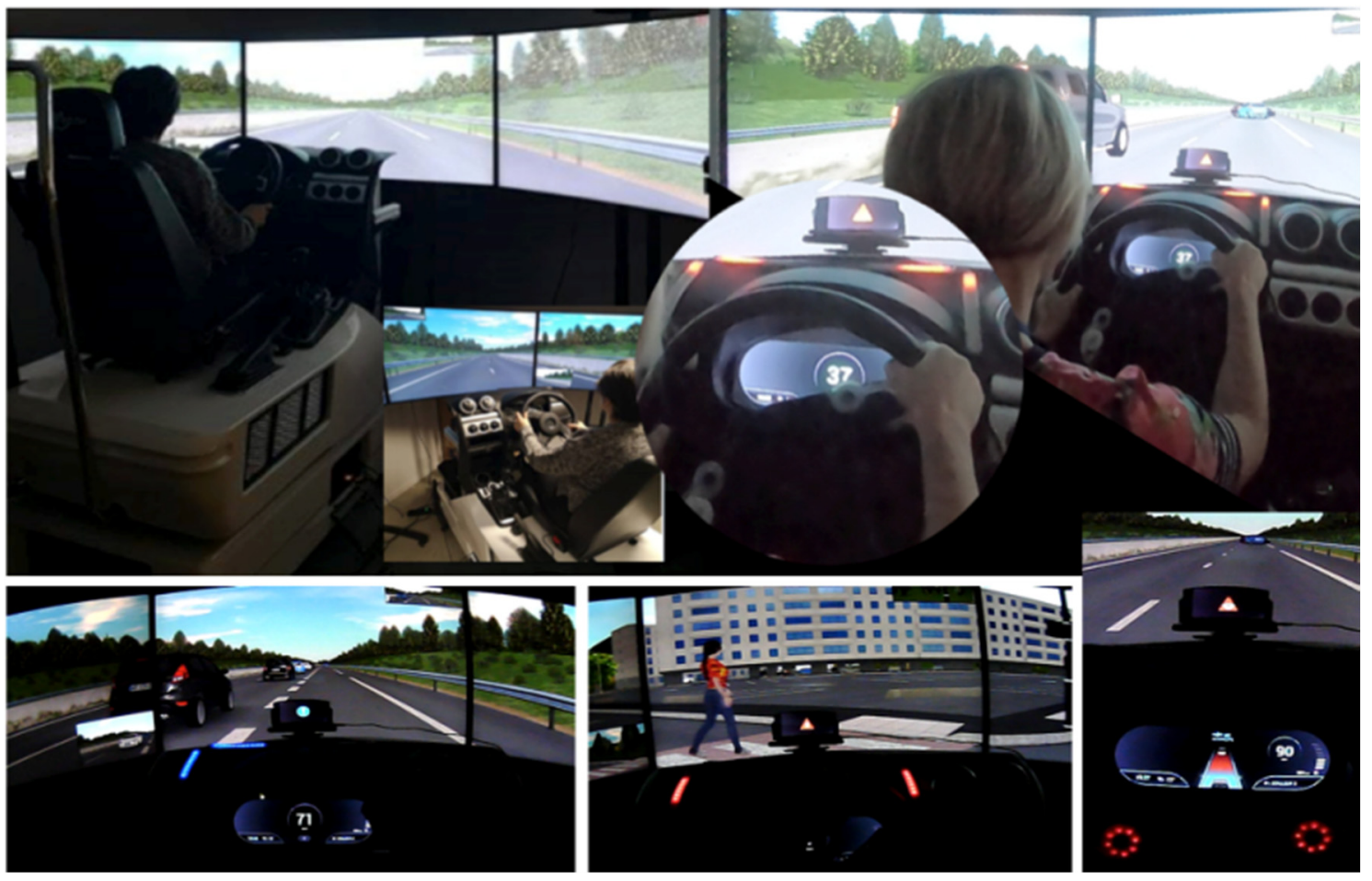

Figure 8. User experience tests as implemented on driving simulator.

\subsection{Participants}

Thirty car drivers were involved in these evaluation tests. They were recruited by a panelist through a preliminary questionnaire combining 3 topics to profile them from their attitude toward vehicle automation: (1) usefulness of vehicle automation, (2) current use of existing ADAS, and (3) willingness to buy autonomous car when available. A last, 
3 groups of ten drivers with very contrasted profiles were recruited: 10 participants having a "positive" attitude (i.e., positive assessment of vehicle automation usefulness, frequent use of ADAS and interested in buying autonomous car in the future), 10 participants with a "neutral" attitude (i.e., quite neutral on the usefulness and interest of vehicle automation) and 10 participants with a "reluctant" attitude (i.e., skeptical about vehicle automation usefulness, poor users of ADAS even if their car is equipped, and with a low willingness to buy an autonomous car). The 30 participants held a valid driving license ( 9 males and 21 female drivers, with a mean age of 42 [S.D. $=11.5]$ ). All of them reported normal or corrected-to-normal vision and hearing. Written informed consent was obtained from each participant prior to the experiment.

\subsection{User Tests Implemented}

The HCAI algorithm evaluation was performed by carried out user tests allowing the participants to practically interact with this new type of "adaptive automation" for different traffic conditions.

In brief, participants experienced the three driving aids by interacting with HMI components (i.e., auditory and visual information). The latter were contextually adapted in real time from the HMT manager, in accordance with the monitoring of (1) the driving behaviors adequacy and (2) the external risk of collision.

Users' experience was at last supported through 12 driving scenarios (5 scenarios for AHiDA-M, 3 for AHiDA-A, and 4 for AICA). Two different types of test scenarios were used for this evaluation: free and controlled scenarios. For the free scenarios, participants have to perform the driving task in a free mode, yet respect general instructions provided by the experimenter (i.e., "follow the lead car at a safe distance"). For the controlled scenarios, the experimenter invited the participants to purposely experience critical behaviors or to deliberately make driving errors, with a view to observe (i.e., to become aware) how driving aid systems will react in the case of dangerous behavior assessed by the HMT manager. Such a controlled approach was required to ensure that all the participants would experience similar systems reactions when confronted with driving errors, even if not made spontaneously by the driver.

\subsection{Evaluation Process}

Participants were first welcomed and the driving simulator experiment was introduced by the experimenter. After this, they had to provide a first assessment about their initial level of acceptability for using an automated vehicle (cf. "after-before use" comparative method adapted from [24], and further presented in Section 5.5).

Then, participants took place in the driving simulator for a $10 \mathrm{~min}$ training session, in order to familiarize themselves with driving on simulator.

After this, participants performed the 12 scenarios of the ADAS experiment. At last, they performed 3 "blocks of situations", corresponding respectively to the experience of the 3 driving aid systems. At the end of each block, a questionnaire adapted from [16] was administered by the experimenter. This questionnaire was used to evaluate the HMT manager algorithm for each ADAS with 5 levels of assessments: system reactions, benefits for road safety, perceived utility, acceptance and satisfaction.

Finally, after having practically experienced the adaptive management of driving aids supported by the HCAI algorithm for the 12 scenarios, participants were invited to complete $2 \mathrm{UX}$ questionnaires to evaluate this new type of vehicle automation:

(1) The SUS questionnaire (system usability scale of Brooke [25]), composed of 10 items.

(2) A short version of the AttrakDiff questionnaire [26,27] composed of 4 items evaluating the pragmatic qualities, 4 items evaluating the hedonic qualities, and 2 items evaluating the attractiveness of this new type of vehicle automation. 


\section{Evaluation Results}

The evaluation of the HMT Manager algorithm was based on the ISO norm 9241-11 [28]. Evaluations were implemented at two complementary levels: at the HCAI algorithm level, on the one hand, and at the driving assistance level, on the other. HCAI algorithm performances were evaluated by considering its efficiency, effectiveness, and impact on user's satisfaction. The driving assistance issue was evaluated by considering the usability and the attractiveness of this innovative solution of HCAI-based automation.

\subsection{HCAI Algorithm Efficiency}

When applied to the HCAI algorithm evaluation, efficiency is related to the technical abilities of this algorithm to assess the situational dangerousness and the drivers' behaviors adequacy in an appropriate way and in an efficient time.

The following Table 1 summarizes the main technical performances (efficient versus Inappropriate) of the HCAI algorithm to adequately manage HMT during the user tests. Synthetically, the number of malfunctioning or inefficient performances, as measured during this experiment on the driving simulator, was very limited (i.e., 1.4\% of inappropriate reactions of the driving aids for a total of 360 scenarios performed by all the participants).

Table 1. Evaluation of the HMT manager efficiency.

\begin{tabular}{ccccc}
\hline & $\begin{array}{c}\text { Number of Inappropriate } \\
\text { Performance }\end{array}$ & $\begin{array}{c}\text { Number of } \\
\text { Scenarios }\end{array}$ & $\begin{array}{c}\% \text { of Inappropriate } \\
\text { Performance }\end{array}$ & $\begin{array}{c}\% \text { of Efficient } \\
\text { Performance }\end{array}$ \\
\hline AHiDA-M & 4 & 150 & $2.7 \%$ & $97.3 \%$ \\
AHiDA-A & 1 & 90 & $1.1 \%$ & $98.9 \%$ \\
AICA & 0 & 120 & $0 \%$ & $100 \%$ \\
All Systems & 5 & 360 & $1.4 \%$ & $98.6 \%$ \\
\hline
\end{tabular}

\subsection{HCAI Algorithm Effectiveness and Impact on Users' SATISFACTION}

When applied to the HCAI algorithm evaluation, effectiveness is related to the accuracy and completeness of this algorithm to manage HMT according to the Human-Centered Design requirements presented in Section 2.2.

In the frame of this study, effectiveness was more specifically assessed from drivers' evaluations about (1) the quality of the HCAI-based system reactions and (2) their benefits for road safety. To provide their evaluations, participants used two 0-100 Likert scales, ranging from 0 (highly negative evaluation) to 100 (highly positive evaluation).

Impact on users' satisfaction, which is more directly related here to the algorithm abilities to assist the drivers according to their needs and expectations towards HMT [28], was also assessed from a Likert scale (from 0 [not satisfied at all] to 100 [highly satisfied]), delivered in association with two additional scales focused on (1) the perceived utility of the HCAI-based management of HMI, and (2) the acceptance for using a vehicle equipped with this new type of adaptive automation.

The motivation for using such type of 0-100 scales came from a previous study implemented by Bellet et al. [16] to evaluate different ADAS in a standardized comparative way, having provided a set of reference values collected for 21 driving aids according to their perceived utility and acceptance (i.e., from "low utility or acceptance" for a score of 20 and less, to "extremely high utility or acceptance" for ADAS obtaining more than 80/100). From this pre-existing study, it is thus possible to appreciate the participants' evaluations about the HCAI algorithm in a comparative way (from highly negative evaluation for 0-20 scores to highly positive evaluation for 80-100 scores).

The following Figure 9 summarizes the 30 participants' judgments about these five dimensions of the HCAI algorithm, as evaluated during the driving simulator experiment. As a global result, the effectiveness of the HCAI algorithm was assessed as very high by the users, with a mean score of 92/100 regarding the adequacy of the system reaction, and of $88.5 / 100$ for the potential benefit for road safety. 


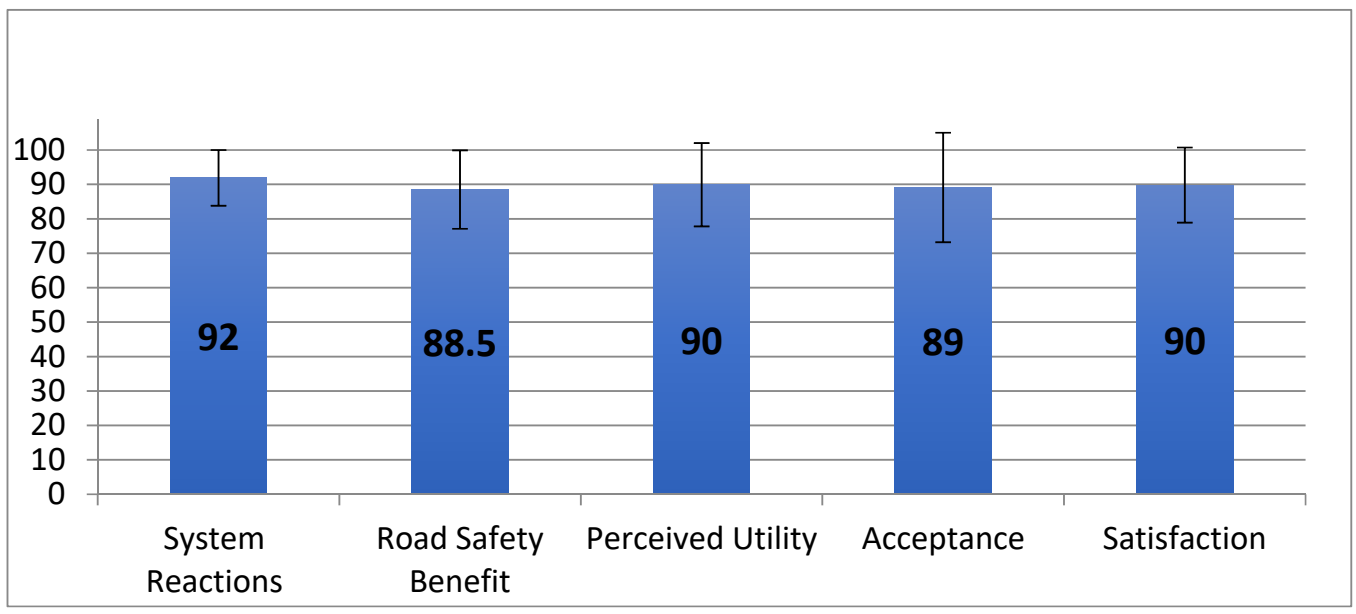

Figure 9. Users' evaluations of the HMT manager performances.

In a similar way, participants' evaluations about the perceived utility as well as of the acceptance for using a car equipped with the HMT adaptive monitoring functions were highly positive (respectively 90 and 89 scores). Finally, the satisfaction of the participants about the HCAI-based management of HMT with vehicle automation was also very high (i.e., 90/100).

Moreover, according to ANOVA tests, there was no significant difference between the three profiles of drivers (i.e., positive, neutral and reluctant) regarding these five dimensions, meaning that all the groups of end users had a at last a very positive opinion about the HCAI algorithm management of human-machine interactions and transitions.

\subsection{Usability of HCAI-Based Vehicle Automation}

The Usability of the vehicle automation solution based on the HCAI algorithm was evaluated from the SUS questionnaire (system usability scale-[25]) composed of 10 items. The main advantage of this questionnaire is to be standardized and to permit the computation of a global "usability score", ranging from 0 to 100.

Moreover, Bangor et al [29] also proposed a calibrated interpretation scale regarding this SUS usability score (Figure 10). When a system obtains a global score lower than 50, it can be assessed as "not acceptable" due to serious problems related to its usability. By contrast, a system will be considered as "good" when obtaining value of 73/100 and more.

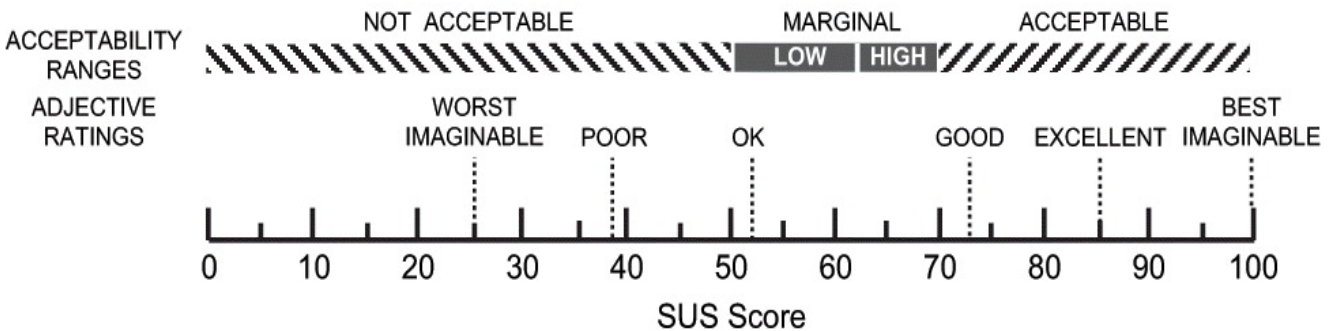

Figure 10. Calibrated scale for interpreting the total score of the system usability scale (SUS) questionnaire [21].

The following Table 2 presents the SUS scores obtained by the HCAI-based vehicle automation among the three profiles of drivers. The average SUS score obtained for all the participants is 81.7 (S.D. = 15). This global score can be assessed as "good", according to the Bangor et al.'s calibration [29]. 
Table 2. SUS score results for each profile of drivers.

\begin{tabular}{ccc}
\hline Drivers Profiles & Mean & S.D. \\
\hline Reluctant & 81 & 18.27 \\
Neutral & 80 & 12.42 \\
Positive & 84 & 16.17 \\
All Profiles & 81.67 & 15.35 \\
\hline
\end{tabular}

In addition, there is no significant statistical difference between drivers' profiles according to the ANOVA tests. This finding is very encouraging, because it shows that the driving aids based on the HCAI algorithm are positively accepted and assessed by the "technology-friendly" drivers of our panel as well as by drivers having a reluctant attitude toward vehicle automation.

\subsection{AttrakDiff Questionnaire Results}

Although acceptance and usability are focused on the utilitarian qualities of systems, a whole range of new concepts and measures were developed more recently like emotional usability [30], pleasure [31] or hedonic qualities [32,33]. These non-utilitarian qualities are grouped into the field called user experience [25]. While UX evaluations are still associated with traditional concepts or models related to pragmatic qualities of a system (like usefulness or usability), they also consider users' feeling when interacting with this system, which contribute directly to a positive (versus a negative) experience of the end users $[34,35]$.

In the frame of this study, UX evaluations of the HCAI driving aids were based on the short version of the AttrakDiff questionnaire proposed by [27] and translated by Lallemand and Gronier [35], including 4 antonymic scales to evaluate their pragmatic qualities (i.e., complicated-simple, confusing-clear, impractical-practical, unpredictable-predictable), 4 items evaluating their hedonic qualities (i.e., tacky-stylish, unimaginative-creative, dull-captivating, cheap-premium), and 2 items evaluating their attractiveness (i.e., ugly-attractive, bad-good).

The AttrakDiff questionnaire is used to measure a positive versus negative user experience from antonymic scales, from a score ranging from " 3 " (i.e., highly negative evaluation) to " +3 " (i.e., highly positive evaluation).

The users' evaluation scorings collected during our experiment are presented in Figure 11. All of them indicate that the participants had a positive user experience. The highest scores were obtained for the hedonic qualities with an average of 1.95, closely followed by the pragmatic quality (1.92). The lowest score is attractiveness, with a mean value of 1.75 , which is nevertheless also a positive assessment.

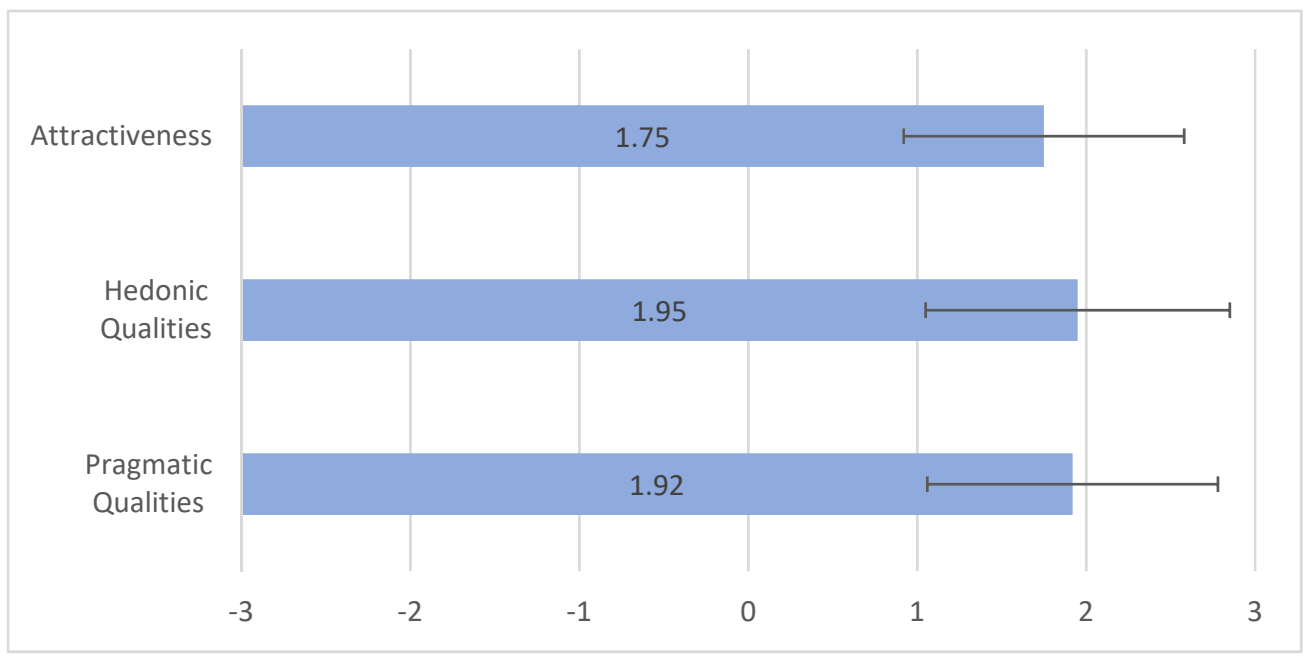

Figure 11. Results for the 3 dimensions evaluated with the AttrakDiff questionnaire. 
The following graph (Figure 12) presents in a more detailed way the average scores collected for each item of the AttrakDiff questionnaire. In a general way, all the items obtained a positive average score, with 6 of them assessed with highly positively values by the end users.

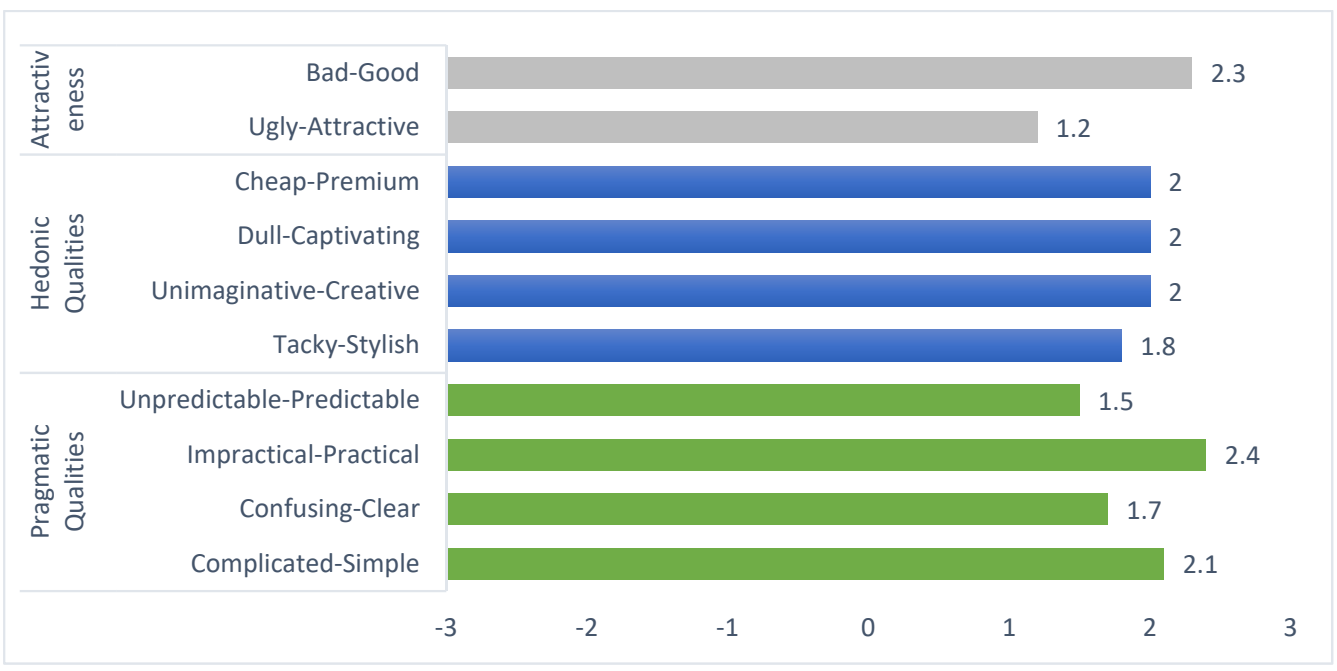

Figure 12. Average scorings collected for each item of the AttrakDiff Questionnaire.

\subsection{Effect of the User Experience on Drivers' Intention to Use Automated Vehicles}

To investigate the positive versus negative effects of the immersive experiment on drivers' opinion towards vehicle automation, we compared the participants' judgments about their agreement for using an automated vehicle from a single question, however asked at two different times: "before" the experiment, and "after" the practical experience of the ADAS systems and their adaptive HMI. The question, extracted from [24], was: "if you have the opportunity, would you be agree to use an automated car?" The user was invited to answer on a scale ranging from 0 (no, not at all) to 100 (yes, absolutely).

Results presented in Figure 13 show that participants assigned significantly higher $(\mathrm{t}(29)=-4.336 ; p<0.05)$ agreement values after having experienced the simulated ADAS (mean score of 87 ) than their a priori judgments (mean score of 68.4). In other words, experiencing the three driving aid systems and their adaptive HMI based on the HCAI principle increased participants' intention to use automated vehicles.

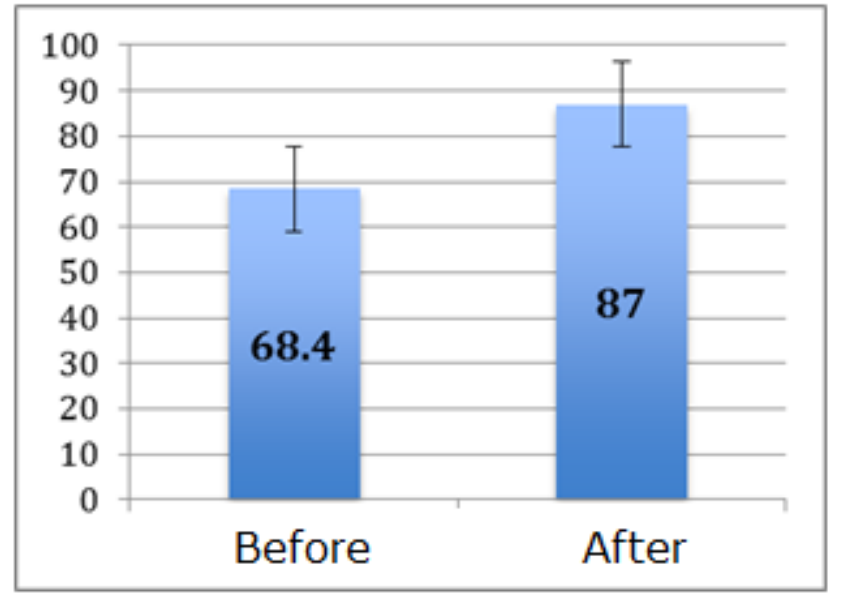

Figure 13. Participants' agreements for using an automated vehicle "before" versus "after" the users experience of HCAI-based automation.

Moreover, when analyzing each profile independently using pairwise comparison (cf. Table 3), we found that the scores collected "after use" for both the neutral $(t(9)=3.466$, 
$p<0.05)$ and the reluctant groups $(\mathrm{t}(9)=2.541, p<0.05)$ were significantly higher than their scores collected "before use". By contrast, this result was not found in the Positive group.

Table 3. Effect of HCAI-based automation experience on drivers' acceptance of automated vehicle.

\begin{tabular}{ccccc}
\hline $\begin{array}{c}\text { Participants' Profiles (Attitude } \\
\text { towards Automated Vehicles) }\end{array}$ & $\begin{array}{c}\text { Agreement } \\
\text { "Before" }\end{array}$ & $\begin{array}{c}\text { Agreement } \\
\text { "After" }\end{array}$ & $\begin{array}{c}\text { After versus Before } \\
\text { "Difference" }\end{array}$ \\
\hline $\begin{array}{c}\text { Reluctant Attitude } \\
\text { (N = 10) }\end{array}$ & $\begin{array}{c}\text { Mean } \\
\text { S.D. }\end{array}$ & 55.1 & 79 & 23.9 \\
\hline Neutral Attitude & Mean & 32.7 & 31.7 & 29.7 \\
$(\mathbf{N}=\mathbf{1 0})$ & S.D. & 65.6 & 91 & 25.4 \\
\hline Positive Attitude & Mean & 30.4 & 11 & 23.2 \\
$(\mathbf{N}=\mathbf{1 0})$ & S.D. & 84.5 & 91 & 6.5 \\
\hline All the participants & Mean & 16.1 & 12.9 & 10.6 \\
$(\mathbf{N}=\mathbf{3 0 )}$ & S.D. & 68.4 & 87 & 18.6 \\
\hline
\end{tabular}

\section{Discussion of the Evaluation Results}

The evaluation method deployed to assess the performances and the benefits of the HCAI-based technology was primarily focused on the end users point of view.

Per hypothesis, it was expected that an adaptive HMT management of vehicle automation when supported by the HCAI algorithm would provide benefits regarding users acceptance and satisfaction, as well as in terms of system usefulness, usability, hedonics qualities and attractiveness.

All the results obtained once participants had practically experienced and interact with this new type of vehicle automation confirm these expectations.

First, findings related to the efficiency of the HMT context-based manager shown a very limited number of malfunctioning of this algorithm $(3 \%)$, attesting that ADAS adaptation evaluated by the drivers were effectively in line with the human-centered design requirements.

Second, evaluations are also very positive regarding both system reactions, benefits for road safety, perceived utility and acceptance, as well as in term of end users' satisfaction. According to the results presented in Figure 9, all these items obtained a score between 88.5 and 92, corresponding to highly positive judgments when compared to the reference values collected by Bellet et al.'s [16] for 21 ADAS systems (i.e., from "low acceptance" for a score of 20 and less, to "extremely high acceptance" for systems obtaining more than 80/100).

Third, in a similar way, findings coming from SUS and AttrakDiff questionnaires are also very positive. The Usability of HCAI-based vehicle automation was assessed as "good" from the SUS questionnaire, by all the profiles of participants. In addition, the results collected form the AttrakDiff indicate "positive evaluations" (i.e., from 1.75 to 2) of pragmatic and hedonic qualities of new type of driving aids. Improvements could be nevertheless made in the future to increase their attractiveness. All these results are however very encouraging regarding the HCAI-based principles to manage human-machine transitions in well-accepted and efficient way.

Finally, when considering the effect of the immersive experience on drivers' attitude toward vehicle automation, the practical experience of the adaptive HMI based on the HCAI algorithm had positively increased their intention to use automated vehicles. When comparing each profile (cf. Table 3), it appears that the scores collected "after use" for both the neutral and the reluctant profiles were significantly higher than their scores collected "before use". This result was not found for the positive group. However, this may be explained by the fact that these drivers, unlike the two other groups, had a very high positive attitude towards vehicle automation before the experiment. Consequently, the benefits of the positive effects when experiencing HCAI-based automation are more limited among them. However, this last finding can be considered as confirmation of their initial positive attitude towards vehicle automation. From the other side, the positive experience induced by the driving simulator experiment among the neutral and reluctant participants are particularly promising, because they indicate that HCAI-based technology 
significantly increase their final agreement for using automated vehicles and may provide at last a positive experience for different profiles of car drivers, including reluctant people.

Finally, at a more general level related to epistemological and methodological considerations for cognitive engineering applied to artificial intelligence, the positive results of this study also demonstrate the benefits and the interest to involve end users at all the stages of the design, development and evaluation process of future products. By integrating drivers' needs (i.e., ergonomics requirements) and difficulties or error risks (i.e., monitoring functions and driving activity model to support the AI algorithm), it has been possible to design a HCAI-based solution able to manage accordingly human-machine interactions and transitions with vehicle automation.

When considering in a systematic way end users' needs, automotive designers enhance their chances to develop vehicle automation corresponding to real drivers' expectations. Positive results of user tests implemented in this study confirm the feasibility and the advantages of such a HCAI-based approach to increase end users' acceptance of future advanced technologies and, at last, to satisfy them in a more efficient way.

\section{Conclusions}

This research focused on the design, development and evaluation of AI technics aiming to adaptively manage driver's interactions with vehicle automation. From a human centered design approach (presented in Section 1), three driving aid systems were first defined. Then, an AI algorithm was developed (presented in Section 2) to support an adaptive HMT context-based Manager (inspired from Bellet et al.'s theoretical framework [10]).

This HMT Manger is in charge of jointly monitoring human driver and traffic situation, to evaluate in real time the adequacy (versus the dangerousness) of drivers' behaviors according to the external risk of collision (based on lateral and/or frontal time to collision with other road users). As outputs, this HCAI algorithm allowed the identification of (1) the type of driving aid and (2) the most relevant H-M Transition (i.e., HMT) required in a given driving context. Then, it led to (3) manage accordingly the HMI components for interacting with a driver in the most appropriate way (from information or warnings delivery to vehicle automation take-over).

To evaluate the benefits of this HCAI algorithm from the end user point of view, an immersive experiment (i.e., presented in Section 3) was carried out on a driving simulator, involving three different profiles of drivers (i.e., having a positive, neutral or negative attitude towards automated vehicles).

Final evaluation results (presented in Section 4 and discussed in Section 5) confirmed the benefit and interest of such HCAI algorithm to support HMT, as experienced by the participants on the driving simulator for both (1) assisting their driving task in an adaptive way and (2) increasing their overall acceptance of automated vehicles.

This last result is of prior importance, as IA technics for future vehicle automation is not only a technical issue. Indeed, the main challenge is to design HCAI-based driving aids that are assessed as useful and that are well accepted by the future end users.

\section{Limitations}

The main limitation of this study relates to the fact that the developed algorithm has been evaluated on a driving simulator, for a limited number of driving situations, and that it was tested among a reduced number of end users. Substantial efforts will still be necessary to have operational and efficient "cooperative automation functions" on real vehicles. However, the same methodological approach could be deployed for this purpose to design and evaluate an HCAI-based algorithm in real vehicle.

Author Contributions: Conceptualization was performed by T.B. and A.B.; methodology was designed and implemented by T.B., M.P. and A.B. Software was designed by T.B. and B.R., and implemented by B. Richard and J.Q.; data processing was performed by M.P., A.B. and T.B.; paper was written by T.B. and A.B. All authors have read and agreed to the published version of the manuscript. 
Funding: This research was conducted within the European project VI-DAS (Vision Inspired Driver Assistance Systems; http:/ / www.vi-das.eu), and has received funding from the European Union's Horizon 2020 Research and Innovation Programme, under grant agreement No 690772.

Institutional Review Board Statement: Not applicable.

Informed Consent Statement: Not applicable.

Data Availability Statement: Not applicable.

Conflicts of Interest: The authors declare no conflict of interest.

\section{References}

1. Hollnagel, E.; Woods, D.D. Joint Cognitive Systems: Foundations of Cognitive Systems Engineering; CRC Press: Boca Raton, FL, USA, 2005.

2. Hoc, J.-M.; Young, M.S.; Blosseville, J.-M. Cooperation between drivers and automation: Implications for safety. Theor. Issues Ergon. Sci. 2009, 10, 135-160. [CrossRef]

3. Young, M.S.; Stanton, N.A.; Harris, D. Driving automation: Learning from aviation about design philosophies. Int. J. Veh. Des. 2007, 45, 323. [CrossRef]

4. Merat, N.; Lee, J.D. Preface to the special section on human factors and automation in vehicles: Designing highly automated vehicles with the driver in mind. Hum. Factors 2012, 54, 681-686. [CrossRef] [PubMed]

5. $\quad$ Kyriakidis, M.; De Winter, J.; Stanton, N.A.; Bellet, T.; Van Arem, B.; Brookhuis, K.; Martens, M.H.; Bengler, K.; Andersson, J.; Merat, N.; et al. A human factors perspective on automated driving. Theor. Issues Ergon. Sci. 2017, 20, 223-249. [CrossRef]

6. Davis, F.D. A Technology Acceptance Model for Empirically Testing New End-User Information Systems: Theory and Results. Ph.D. Thesis, Massachusetts Institute of Technology, Cambridge, MA, USA, 1986.

7. Venkatesh, V.; Morris, M.G.; Davis, G.B.; Davis, F.D. User acceptance of information technology: Toward a unified view. MIS Q. 2003, 27, 425-478. [CrossRef]

8. Madigan, R.; Louw, T.; Dziennus, M.; Graindorge, T.; Ortega, E.; Graindorge, M.; Merat, N. Acceptance of Automated Road Transport Systems (ARTS): An Adaptation of the UTAUT Model. Transp. Res. Procedia 2016, 14, 2217-2226. [CrossRef]

9. Bellet, T.; Hoc, J.M.; Boverie, S.; Boy, G.A. From human-machine interaction to cooperation: Towards the integrated co-pilot. In Human-Computer Interaction in Transport; Kolski, C., Ed.; Ashgate: Farnham, UK, 2011; pp. 129-156.

10. Bellet, T.; Cunneen, M.; Mullins, M.; Murphy, F.; Pütz, F.; Spickermann, F.; Braendle, C.; Baumann, M.F. From semi to fully autonomous vehicles: New emerging risks and ethico-legal challenges for human-machine interactions. Transp. Res. Part F Traffic Psychol. Behav. 2019, 63, 153-164. [CrossRef]

11. Taxonomy and Definitions for Terms Related to on-Road Motor Vehicle Automated Driving Systems. 2014. Available online: https://www.sae.org/standards/content/j3016_201806/(accessed on 30 December 2020).

12. De Raedt, R.; Ponjaert-Kristoffersen, I. Predicting at-fault car accidents of older drivers. Accid. Anal. Prev. 2001, 33, 809-819. [CrossRef]

13. Lyman, S.; Ferguson, S.A.; Braver, E.R.; Williams, A.F. Older driver involvements in police reported crashes and fatal crashes: Trends and projections. Inj. Prev. 2002, 8, 116-120. [CrossRef]

14. Clarke, D.D.; Ward, P.; Bartle, C.; Truman, W. Older drivers' road traffic crashes in the UK. Accid. Anal. Prev. 2010, 42, 1018-1024. [CrossRef]

15. Freeman, J.; Scott-Parker, B.; Wong, I.; Haworth, N. Vulnerable road user groups: A review of younger drivers, motorcyclists and older drivers. Vulnerable Groups Incl. 2012, 3. [CrossRef]

16. Bellet, T.; Paris, J.-C.; Marin-Lamellet, C. Difficulties experienced by older drivers during their regular driving and their expectations towards Advanced Driving Aid Systems and vehicle automation. Transp. Res. Part F Traffic Psychol. Behav. 2018, 52, 138-163. [CrossRef]

17. Sagberg, F.; Bjørnskau, T. Hazard perception and driving experience among novice drivers. Accid. Anal. Prev. 2006, 38, 407-414. [CrossRef] [PubMed]

18. DeLucia, P.R.; Bleckley, M.K.; Meyer, L.E.; Bush, J.M. Judgments about collision in younger and older drivers. Transp. Res. Part F: Traffic Psychol. Behav. 2003, 6, 63-80. [CrossRef]

19. Underwood, G.E. Visual attention on the transition from novice to advanced driver. Ergonomics 2007, 50, 1235-1249. [CrossRef]

20. Bellet, T.; Bailly-Asuni, B.; Mayenobe, P.; Banet, A. A theoretical and methodological framework for studying and modelling drivers' mental representations. Saf. Sci. 2009, 47, 1205-1221. [CrossRef]

21. Paris, J.C.; Bellet, T.; Marin-Lamellet, C.; Cour, M.; Boverie, S.; Claverie, B. Assistance aux Conducteurs âgés: Analyse de l'activité pour la Conception de Futures Fonctions de Monitorage de la Conduite Automobile. 2014, pp. 227-243. Available online: https:/ / hal.archives-ouvertes.fr/hal-01326509/document (accessed on 30 December 2020).

22. Georgeon, O.L.; Mille, A.; Bellet, T.; Mathern, B.; Ritter, F.E. Supporting activity modelling from activity traces. Expert Syst. 2011, 29, 261-275. [CrossRef]

23. Bellet, T.; Deniel, J.; Bornard, J.C.; Richard, B. Driver Modeling and Simulation to support the Virtual Human Centered Design of future Driving Aids. In Proceeding of the INCOSE International Conference on Human-Systems Integration (HSI2019), Biarritz, France, 11-13 September 2019. 
24. Distler, V.; Lallemand, C.; Bellet, T. Acceptability and acceptance of autonomous mobility on demand: The impact of an immersive experience. In Proceedings of the 2018 CHI Conference on Human Factors in Computing Systems, Montreal, QC, Canada, 21-26 April 2018; pp. 612-617.

25. Brooke, J. SUS: A retrospective. J. Usability Stud. 2013, 8, 29-40.

26. Hassenzahl, M.; Burmester, M.; Koller, F. AttrakDiff: Ein Fragebogen zur Messung wahrgenommener hedonischer und pragmatischer Qualität. In Mensch \& Computer 2003. Interaktion in Bewegung; Ziegler, J., Szwillus, G., Eds.; B.G. Teubner: Stuttgart, Germany, 2003; pp. 187-196.

27. Hassenzahl, M.; Monk, A. The Inference of Perceived Usability from Beauty. Human Comput. Interact. 2010, 25, 235-260. [CrossRef]

28. International Organization for Standardization. ISO9241-11 Ergonomic Requirements for Office Work with Visual Display Terminals (VDTs)_Part 11: Guidance on Usability; International Organization for Standardization: London, UK, 2018.

29. Bangor, A.; Kortum, P.; Miller, J.T. An Empirical Evaluation of the System Usability Scale. Int. J. Human Comput. Interact. 2008, 24, 574-594. [CrossRef]

30. Logan, R.J. Behavioral and emotional usability: Thomson consumer electronics. In Usability in Practice; Academic Press Professional Inc.: Cambridge, MA, USA, 1994; pp. 59-82.

31. Jordan, P.W. Designing Pleasurable Products: An Introduction to the New Human Factors; CRC Press: Boca Raton, FL, USA, 2002.

32. Hassenzahl, M. The Effect of Perceived Hedonic Quality on Product Appealingness. Int. J. Human Comput. Interact. 2001, 13, 481-499. [CrossRef]

33. Hassenzahl, M. User Experience (UX): Towards an Experiential Perspective on Product Quality. In Proceedings of the 20th International Conference of the Association Francophone d'Interaction Homme-Machine on-IHM '08, Metz, France, 2-5 September 2008; pp. 11-15.

34. Hassenzahl, M.; Tractinsky, N. User experience-A research agenda. Behav. Inf. Technol. 2006, 25, 91-97. [CrossRef]

35. Lallemand, C.; Gronier, G. Méthodes de Design UX: 30 Méthodes Fondamentales pour Concevoir et Évaluer les Systèmes Interactifs; Editions Eyrolles: Paris, France, 2015. 